\title{
Children's vulnerability to health damages: elements, applicability and perspectives
}

\author{
Daniel Ignacio da Silva ${ }^{1}$, Débora Falleiros de $\mathrm{Mello}^{2}$, Renata Ferreira \\ Takahashi $^{1}$, Maria de La Ó Ramallo Veríssimo ${ }^{1}$ \\ ${ }^{1}$ School of Nursing, University of São Paulo, São Paulo, Brazil ${ }^{2}$ College of Nursing, University of São Paulo at \\ RibeirãoPreto, Brazil.
}

\begin{abstract}
:
Aim and design: This is a reflexive study that aims to present the elements of children's vulnerability to health damage. This discussion is focused on the conceptual framework of vulnerability and its potential contributions for children's health promotion.

Discussion: Children are vulnerable to suffer health damages due to the influence of elements from their individual characteristics and environment. The analysis of vulnerable situations in child health and the impairments arising from them should consider familiar, affective, social, economic, political and programmatic elements.

Final considerations and recommendations for future research: The applicability of this set of elements in the perspective of care, assessment and planning of public policies allows a new foresight about child care, as well as it may help delineate new theoretical and observational studies in the child health area. Investigations in this area are necessary because vulnerability is an incipient theme in health sciences, which demands improvement to apply this concept in the field of child health care. These future research studies may allow the reorientation of care model, stimulate the overcoming of the biological and fragmented concept of health diagnosis and promote social responses that foster child health and its development.

Keywords: Health Vulnerability, Comprehensive Health Care, Child Health (Public Health).
\end{abstract}

\section{Introduction}

Child care requires knowledge and practices that permeate the advance of comprehensive child care, aiming to decrease mortality and illnesses, to promote a healthy development and growth, as well as rights advocacy [1].

Interventions in health disorders, life conditions and social determinants imply an increase in the understanding about vulnerable situations. Several studies have pointed to the relevance of deepening the health analysis, considering the vulnerability of people and groups, their components, a variety of factors and magnitude, as well as the repercussion of health disparities and inequalities [2-5].In that sense, it is relevant to widen the recognition of the elements that permeate children's vulnerability to health damages to identify interventions that result in improvements in the quality of child care [6].

Furthermore, the elements that comprise children'svulnerability to health damages are the central object in the present paper. The acknowledgement of these elements provides subsidies for the practice of health professionals and managers in order to shape care plans grounded in children's specific needs against adverse situations that may impair their health and life quality [7]. Thus, this reflexive paper aimed to present the elements of children to health damages. This discussion is focused on the conceptual framework of vulnerability and its potential contributions to children's health promotion.

\section{The origins of the vulnerability concept and its application in health practices}

The term vulnerability was originated in the area of international defense for universal human rights, having the meaning of groups and subjects incapable to promote, protect or ensure their citizen's rights in the juridical and political scope[8]. Thus, the use of this concept in the Health area resulted from an integrated action of activism and the human rights movement as a control measure of AIDS pandemic [9].

In this paper, vulnerability is understood as a complex of conditions that make subjects and groups more susceptible to illnesses or disabilities, due to the influence of elements of individual, social and programmatic nature [9].

The individual dimension of vulnerability is related to elements of cognitive and behavioral nature as the available knowledge for people and their competence to organize their decisions about their health condition [9]. The social dimension is concerned not only with access to education, citizen's rights and social welfare, but also equality of gender, ethnicity, sexual orientation and capability of social mobilization [9]. Hence, the programmatic dimension is associated with policies and health programs and the government commitment in 
making the resources available, and manage and monitor the preventive actions [9].

The understanding of the concept of vulnerability allows the acknowledgement of health needs and the development of interventions that strengthen the healthy environments of life, as well the health potential of population in favor of their quality of life [10-11]. The recognition of vulnerability expands the understanding of the health-illness process and stimulates the changes in the technical healthcare models as social, historic and intersectoral ones[10].

The concept of vulnerability opposes to the concept of probabilistic risk, which is traditionally used in epidemiological practices and studies [10]. The concept of risk evolved from a generic reading about unhealthy conditions of life - Epidemiology of Constitution - as well as from a statistical and quantitative view in order to measure the phenomena and their relationship between cause and outcomes - Epidemiology of Exposition and Risk [12]. The concept of risk assesses the mathematical chances for people to get ill when they possess characteristics and/or behaviors that identify them with those suffering from a certain illness. However, the concept of vulnerability evaluates the potential for illness or not of a person or group who are under the same conditions $[\mathbf{1 0}, \mathbf{1 2}]$. This association aims to identify, between population, what people are more susceptible to be sick or to suffer harm, in order to adopt preventive actions or barriers to the advance of illness [9-10]. These conceptual features show that the risk has limitations about subjective situations, such as experiences or meanings and, consequently, holds its impact in the process of ailment [10, 12].

In another way, the concept of vulnerability has synthetic nature and seeks to identify biological, social, contextual and political elements, which increase the exposure of people and groups to infection or other adverse situations [10]. The concept of vulnerability aims to propose interventions based on the health needs and stimulate a social response and people's autonomy in care and health preservation [2, 9-10].

Thus, it is considered that the identification of people's vulnerabilities from their needs can be a very useful tool for health care, as a time to exchange knowledge and establish bonds [13]. Likewise, the application of vulnerability in care practice can allow the preservation of health through comprehensive and humanized care [14]. However, we need to take into account that people's vulnerability for any phenomena is dynamic, regarding both, its dimensions as well as its degree. Such elements may change over time if its elements suffer change.

The incorporation of vulnerability in the Health team's daily practice enables the planning of actions and technological tools, as well as the assessment of health services and programs [15-16]. This manuscript assumes that the concept of risk is already widely spread in the health field and has relevant interfaces with vulnerability, so it is important to study and scientifically operationalize vulnerability in order to prevent the use of this concept as the risk, in general terms, with the possibility to hinder or limit the reading of reality.

In face of the potential of applicability presented, it is understood that vulnerability may be an important reference for building care technologies in Child Health [7]. Such relevance may be seized if children are considered as a social subject with particular characteristics [6], and with their needs that should be considered according to their vulnerabilities, recognizing that care provided to children has a decisive role in the development of their potential $[5,7]$.

\section{Children's vulnerability to health damages and its elements}

The study of vulnerability elements in the context of Child Health is justified by the fact that although there were advances reached by programmatic actions in many countries [7], still a lot of children around the world and in our nation, suffer neglect, lack of care and ongoing caregivers, besides having many impairments in their development by experiencing the violence in armed conflicts, both in war as well as in the urban context, due to the presence of criminal groups and drug dealers [18-19].

These situations are shown as adverse by outcomes found in Neuroscience, Molecular Biology, Epigenetics and Social and Behavioral Sciences. There is evidence that significant adversity may lead to excessive activation of response systems to stress, that may bring damages to brain development [20]. The influence received by children during their early childhood will determine their educational success, their health conditions along their life, also their capacity for economic productivity and their role as a responsible citizen $[17,20]$.

Children need positive interactions and proper care in order to reach adequate academic and professional performance, such as social integration, physical and mental health, and less tendency to criminality and other harmful life practices, as substance abuse. Such care should be ongoing and carried out by committed people to children's welfare, through excellent affective, social, educational and health opportunities. However, adverse environmental situations may produce meaningful changes in the brain architecture, especially when children are mistreated and deprived of external care both within the family or within social institutions [17].

Thus, it is considered that children are vulnerable to health damages when they are exposed to adverse situations either in their family context or in the social institutions [7]. Therefore, children suffer influence of 
their family insertion in the social production, access to consumption and right to health care, education and social promotion policies [21-22]. In the same way, children's vulnerability is interlinked with political guidelines health teams' care models. It is understood that health systems managers and health professionals must develop their care process based on the unalienable and unconditional right of the child to have quality of life [7, 21-22]. Therefore, children's vulnerability tohealth damages may be considered a complex of conditions that determine children's diseases, health damages or impairments, also involving their growth and development $[7,22]$.

\section{Elements of Individual Vulnerability}

Thus, in the individual dimension, vulnerability comprises biological, behavioral and affective elements [9]. Children may be vulnerable owing to the influence of the type of family in which they live, which is characterized by mothers' marital status, the number of family members and by the weak bonds in child care [23-24].

Aggregated with the family situation, studies show that young mothers, associated with their disease condition [25-26], may be elements that undermine child health care and promotion due to caregivers' failure to form emotional bonds with children [23].

Whereas the bond is essential for child development [7], substance abuse and domestic violence are presented as disruptive of caring ties and as elements that increase children's vulnerability to get sick and have their rights violated [24, 26-27].

Associated with children's family situation, the gaps in the social support network are identified as a complicating factor in children's care process. Such gaps may cause a precarious situation in child care, considering that the family, within a capitalist society and due to the labor market conditions, may not supply children's needs alone[26].

However, this social network may influence children's care process negatively, such as the pressure and influence to weaning. This pressure occurs due to the beliefs and personal values of those who live with the nursing mothers or those who care and surround the children. These situations show the relevance of culture and subjective values as elements of vulnerability [28].

Added to culture and personal values, the difficulties of family caregivers in understanding diagnoses, prescriptions and developing actions to promote child health, are described as elements of vulnerability. Nonetheless, this characteristic should be apprehended by social conditions of illiteracy and by lack of family access to educational resources [22, 29].

Mother's adherence to prenatal care has been viewed as a major element of vulnerability, because it is determined by women's behavior and influences child health, including mainly his/her development [7]. However, the type of delivery, gestational age, child health condition and congenital diseases are recognized as elements of risk. Nevertheless, these elements have interface with vulnerability because a lot of them are avoidable and have important potential of intervention by health team. Such interventions have connection with programmatic vulnerability and demand public endeavors for its implementation [7].

Thus, in this context, situations as low birth weight and prematurity [30], history of child health [21] and clinical fragility of children with special needs [31] are situations that require intervention or programmatic actions that may improve children's living conditions.

\section{Elements of Social Vulnerability}

The social dimension of vulnerability comprises elements of economic, contextual and cultural nature [9]. Within this dimension, the degree of caregivers' literacy, shown as an element of vulnerability [22-23, 26] that defines other vulnerability elements, such as caregivers' understanding on the orientation for child care [22, 29], family access to the labor market and to skilled jobs and sustainable incomes $[\mathbf{2 6 , 3 0 ]}$.

Employment and income are considered relevant in the vulnerability analysis, because they define family conditions to provide material resources to supply their children's needs [7]. Otherwise, maternal remunerated work was evidenced as a strong influence of child malnutrition in populations with high social vulnerability [30]. Maternal employment itself shows that there are considerable gaps in the social support network and the precariousness of educational policies [26]. The maternal remunerated work is related to new models of family and single mothers in the postmodern society, who by an unequal way, are compelled to care and feed their children, without support [25].

Within the context of the family's social insertion, housing conditions stand out, such as lack of sanitation, access to treated water and precarious residences may make children vulnerable to diseases and health impairments [22-23]. Housing conditions are related to the vulnerability of exposure to urban violence and drug trafficking which stand out as negative influences to child health [24-27]. Associated with urban violence and drug trafficking, infant work is identified as a vulnerability element because it deprives children of their rights to play, study and live adequate experiences to their age, which are necessary to their development 
[27].

Another element may stand out in the perspective of children's rights, which is the prejudice that they suffer from, owing to their condition of a chronic illness, mainly in the oncology context and that of children with disabilities. This prejudice is related to the social stigma that many families suffer due to people's misunderstanding about such illnesses, associated or not with the representation in the social mindset $[\mathbf{2 9 , 3 1 ]}$.

Still in the social dimension, the access to education, health services and social assistance stand out as elements which may decrease or increase children's vulnerability, owing to their role in strengthening families to provide care $[22,26-27,29,31]$.

\section{Elements of Programmatic Vulnerability}

The programmatic dimension of vulnerability is set by the way that public policy programs and other State actions have been sought to meet children's and their families' needs[7, 21]. Within this situation, State weakness in providing policies that guarantee child health stand out as a vulnerability element. These weaknesses may be characterized by low public budgets for social policies [32].

These budget gaps make precarious team's labor conditions due to the low supply of human resources and by unsuitable child care facilities. These weaknesses disclose governmental contradictions that assert that they really have a political commitment with childhood [32]. For example, it can be pointed out the Statute of Children and Adolescent, which was sanctioned in 1990 and seeks to guarantee children and adolescents' rights and their total protection[27]. Although, in practice, governments deny their rights with frail and minimum policies focused on the poorest [32].

The lack of commitment may be described by the absence of intersectoral actions in child care. Absence of intersectoral interventions jeopardizes comprehensive child care, because it corroborates the biological and fragmented idea of children's illness-health process [32].

Along with issues of the political scenario, the unavailability of programs that meet children's needs may be pointed as an element of vulnerability because it harmsfamily access to comprehensive health care, and may also impact infant epidemiological indicators [29, 31-32].

Within this care context, default of equality is noteworthy as a vulnerability element due to the absence of active listening of family needs and also by lack of a democratic and open dialogue with users of health services $[\mathbf{2 8}, \mathbf{3 2}]$.

The lack of equality in health care influences children'sfair access to health systems, and has the absence of comprehensiveness as an aggregated vulnerability element. This concept may be understood as no guarantee of children's access to all available resources for their recovery, prevention and promotion of health and by the lack of inter and multidisciplinary actions [29, 31-32].

Figure 1, below, synthesizes the elements of vulnerability discussed in this reflexive paper, and they are organized according to the dimensions of children's vulnerability to health damages:
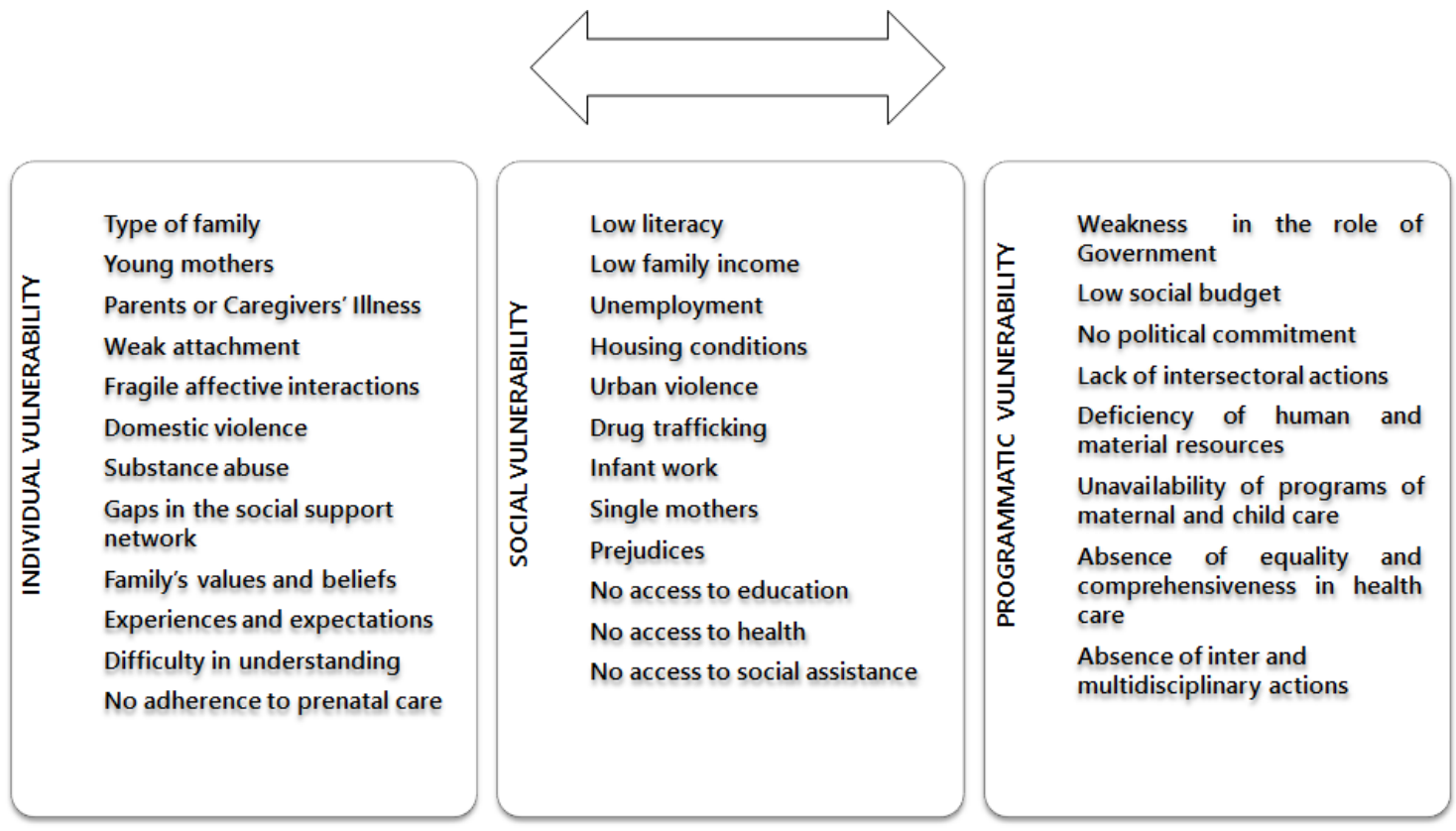

Figure 1 - Elements of children's vulnerability to health damages, according to their dimension [22-32]. São Paulo, 2016. 


\section{Final considerations}

This study sustained that children may be vulnerable to health damages by the influence of elements of several attributes. Thus, the analysis of vulnerable situations in child health and the impairments arising from them should consider family, affective, social, economic, political and programmatic elements.

\section{Recommendations for future research}

The applicability of these elements in the perspective of care, assessment and planning of public policies allows new outlook for child care, as well as it may delineate new theoretical and observational studies in the child health area. These studies have been shown necessary because vulnerability is an incipient theme in health sciences, which demands empirical investigations.

This concept may be applicable to several areas of epidemiology investigations, as well as to care programs in many disciplines of Health Sciences, according to their interdisciplinary attributes. These future research studies may allow the reorientation of the care model, stimulate the overcoming of the biological and fragmented concept of health diagnosis, and promote social responses that foster children's health and their development.

\section{References}

[1]. AJ Barros, C Ronsmans, H Axelson, Loaiza E, Bertoldi AD, França GVA, et al. Equity in maternal, newborn, and child health interventions in Countdown to 2015: a retrospective review of survey data from 54 countries. Lancet 2012- 379(9822):1225-33. doi:10.1016/S0140-6736(12)60113-5

[2]. Shi L, Stevens GD, Lebrun LA, Faed P, Tsai J. Enhancing the measurement of health disparities for vulnerable populations. J Public Health ManagPract. 2008; 14 Suppl:S45-52. doi: 10.1097/01.PHH.0000338386.59565.dc

[3]. Dorsen C. Vulnerability in homeless adolescents: concept analysis. J AdvNurs. 2010; 66(12):2819-27. doi: 10.1111/j.13652648.2010.05375.x

[4]. Grabovschi C, Loignon C, Fortin M. Mapping the concept of vulnerability related to health care disparities: a scoping review. BMC Health Serv Res. 2013; 13: 94. doi: 10.1186/1472-6963-13-94

[5]. Arora SK, Shah D, Chaturvedi S, Gupta P. Defining and measuring vulnerability in young people. Indian J Community Med. 2015; 40(3):193-97. doi: 10.4103/0970-0218.158868

[6]. Mazza VA, Chiesa AM. Family needs on child development in the light of health promotion. Online Braz J Nurs. 2008; 7(3). doi: $10.5935 / 1676-4285.20081852$.

[7]. Silva DI, Chiesa AM, Veríssimo MLOR, Mazza VA. Vulnerability of children in adverse situations to their development: proposed analytical matrix. Rev Esc Enferm USP. 2013; 47(6):1397-402. doi: 10.1590/S0080-623420130000600021

[8]. Kalipeni E. Health and disease in southern Africa: a comparative and vulnerability perspective. SocSci Med 2000;50(7-8):965-83. doi: 10.1016/S0277-9536(99)00348-2

[9]. Ayres JRCM, Paiva V, França Junior I. From natural history of disease to vulnerability. In: Parker R, Sommer M. Routledge. Handbook in Global Public Health. New York: Routledge; 2011. doi: 10.4324/9780203832721.ch10

[10]. Nichiata LYI, Bertolozzi MR Takahashi RF. The use of the "vulnerability" concept in the nursing area. Rev Lat Am Enferm. 2008; 16(5):923-28. doi: 10.1590/S0104-11692008000500020

[11]. Nakamura E, Egry EY, Campos CMS, Nichiata LYI, Chiesa AM, Takahashi RF. The potential of an instrument to identify social vulnerabilities and health needs: collective health knowledge and practices. Rev Lat Am Enferm. 2009;17(2):253-258. doi: 10.1590/S0104-11692009000200018

[12]. Ayres JRCM. The historical and epistemological development of epidemiology and the concept of risk.Cad. Saúde Pública. 2011; 27(7):1301-11. doi: 10.1590/S0102-311X2011000700006

[13]. Sousa PKR, Miranda KCL, Franco AC. [Vulnerability: concept analysis in the clinical practice of nurses from outpatient HIV/AIDS]. Rev Bras Enferm. 2011;64(2): 381-384. doi: 10.1590/S0034-71672011000200026 (In Portuguese)

[14]. Barra DCC, Lanzoni GMM, Maliska ICA, Sebold LF, Meirelles BHS. Human living process and nursing from the vulnerability perspective. Acta Paul Enferm. 2010;23(6):831-836. doi: 10.1590/S0103-21002010000600018

[15]. Cabral FB, Oliveira DLLC. Women's vulnerability in the puerperium from the view of family health teams: emphasis on generational aspects and adolescence. RevEscEnferm USP. 2010;44(2):368-375. doi: 10.1590/S0080-62342010000200018

[16]. Berardinelli LMM, Santos MLSC. [Pedagogical workshop of Nursing: an experience of convergence, care and education]. Rev GaúchaEnferm. 2007; 28(3):430-8. (In Portuguese)

[17]. Bick J, Nelson CA. Early adverse experiences and the developing brain.Neuropsychopharmacology. 2016;41(1):177-96. doi:10.1038/npp.2015.252

[18]. Lloyd E, Penn H, Barreau S, Burton V, Davis R, Potter S, Sayeed R. How effective are measures taken to mitigate the impact of direct experience of armed conflict on the psychosocial and cognitive development of children aged 0-8? In: Research Evidence in Education Library. London: EPPI-Centre, Social Science Research Unit, Institute of Education, University of London; 2005.

[19]. Milletich RJ, Kelley ML, Doane AN, Pearson MR. Exposure to interparental violence and childhood physical and emotional abuse as related to physical aggression in undergraduate dating relationships. J Fam Violence. 2010 Oct; 25(7):627-37. doi:10.1007/s10896-010-9319-3

[20]. Shonkoff JP. Protecting brains, not simply stimulating minds. Science. 2011; 333(6045):982-983. doi: 10.1126/science. 1206014

[21]. Figueiredo GLA, Mello DF. Child health care in Brazil: aspects of program vulnerability and human rights. RevLatAm Enfermagem 2007; 15(6):1171-6. doi: 10.1590/S0104-11692007000600018

[22]. Pedroso MLR, Motta MGC. [Comprehension of social and economic vulnerability in the scenario of pediatrics nursing care].RevGauchaEnferm. 2010; 31(2):218-45. (In Portuguese)

[23]. Oliveira LN, Breigeironb MK, Hallmanna S, Witkowskia MC. Vulnerabilities of children admitted to a pediatric inpatient care unit. Rev Paul Pediatr. 2014; 32(4):367-73. doi: 10.1590/S0103-05822014000400013

[24]. Silva DI, Maftum MA, Mazza VA. Vulnerability in child development: influence of weak family bonds, substance abuse and domestic violence. Texto\&ContextoEnf. 2014; 23(4):1087-94. doi: 10.1590/0104-07072014001700013

[25]. Silva DI, Mazza VA. Vulnerability in child development: the influence of the mother's youth and health conditions. 
CogitareEnfermagem. 2014; 19(2):217-23.

[26]. Mello DF, Pancieri L, Wernet M, Andrade RD, Santos JS, Silva MAI. [Vulnerability in childhood: mothers' experiences in caring for their child's health]. Rev. Eletr. Enf. 2014; 16(1):52-60. doi: 10.5216/ree.v16i1.21134 (In Portuguese)

[27]. Fonseca FF, Sena RKR, Santos RLAD, Dias OV, Costa SDM. The vulnerabilities in childhood and adolescence and the Brazilian public policy intervention.Rev. Paul. Ped. São Paulo. 2013; 31(2):258-64. doi: 10.1590/S0103-05822013000200019

[28]. Souza SNDHD, Mello DFD, Ayres JRCM. [Breastfeeding from the perspective of programmatic vulnerability and care].Cad. saúdepública. 2013; 29(6):1186-94. doi: 10.1590/S0102-311X2013000600015 (In Portuguese)

[29]. Motta MGC, Diefenbach GDF. Dimensions of vulnerability for the family of the child with oncologic pain in the hospital environment.Escola Anna Nery. 2013; 17(3):482-90. doi:10.1590/S1414-81452013000300011

[30]. Vieira VL, Cervato-Mancuso AM. [Maternal work and child malnutrition in an area of high social vulnerability].Pediatria (São Paulo). 2010;32(3):177-83. (In Portuguese)

[31]. Silveira AD, Neves ET. [Children with special health care needs: family care in preserving life]. Ciênc. cuid. Saúde. 2012; 11(1):74-80. doi: 10.4025/cienccuidsaude.v11i1.18861 (In Portuguese)

[32]. Silva DI, Veríssimo MLOR, Mazza VA. Vulnerability in child development: influence of public policies and health programs. J Hum Growth Dev. 2015; 25(1):11-18. doi:10.7322/jhgd.96760 